\title{
The Process of Ultra Low-Volume Seed Etching by an Experimental Device
}

\author{
Sergey Papusha ${ }^{1, *}$, Filipp Kozhura ${ }^{1}$, and Valeria Zhadko $^{1}$ \\ ${ }^{1}$ Kuban State Agrarian University named after I.T. Trubilin, Krasnodar, Russia
}

\begin{abstract}
The main way to protect plants from diseases and pests is the treatment of seed material with pesticides. To achieve maximum efficiency from complex seed treatment, it is necessary to evenly distribute the drug over the surface of all available seeds. One of the conditions for operation of the etcher is the possibility of connecting to the compressor unit and the electricity network. The performance of the sprayer was studied depending on the pressure in the pneumatic system of the spraying device and the diameter of the feeding tube.
\end{abstract}

Seed treatment with pesticides is one of the main ways to protect plants from pathogens. In addition, this technique is widely used in protecting plants from sucking and gnawing pests due to intensification of young sprouts. However, high efficiency from complex seed treatments with pesticides is achieved only with uniform application of the drug to the surface of each seed.

The analysis of the work of modern etching machines shows that when processing seeds, a uniform distribution of the drug over their surface is not achieved, the coefficient of unevenness ranges from 0 to $100 \%$.

To intensify the process of seed etching, it is necessary to universalize individual devices, namely seed dispensers and spraying devices. Both of them should be able to be installed both in the mixing chambers of seed etchers, and on the unloading conveyors of seeder loaders and loading and unloading machines. This will make it possible to process seeds with various preparations that cannot be combined with simultaneous processing. In addition, the use of biobacterial preparations for seed treatment during storage should be applied immediately before sowing without exposure to sunlight, which can significantly strengthen the plant's immune system and protect them from diseases and pests [1]. The use of ultra-low-volume treatment of seeds with liquid drugs with high-quality coating with pneumatic slot sprayers will reduce the consumption of the drug and their losses [2].

The practical significance of the study of the experimental device of the KubSAU design is in the use of the proposed scheme of the etcher for processing the seeds during loading and unloading and pre-etching to reduce operating costs and improve the quality of treatment.

The modernized etcher in this way, in a semi-dry way, is capable of treating with water suspensions of pesticides of seeds of cereals, legumes and industrial crops against pathogens transmitted through seeds and to improve the sowing qualities of seeds [3].

\footnotetext{
*Corresponding author: serega0318@mail.ru
} 
The seed etcher is designed for use at grain cleaning points in closed rooms (warehouses, storages) and on indoor storage areas for finished products. The main condition of the use of this machine is to ensure the possibility of connecting to the $380 \mathrm{~V}$ power grid and the air supply system.

The design of the etcher includes a frame, a loading scraper conveyor, a hopper, an unloading auger, a reservoir of working fluid, an equalizing tank, a sprayer [4-7], electrical equipment systems, pneumatic lines from a compressor with a pressure regulator, connecting pipelines and hoses.

The technological process of the upgraded machine is shown in Fig. 1

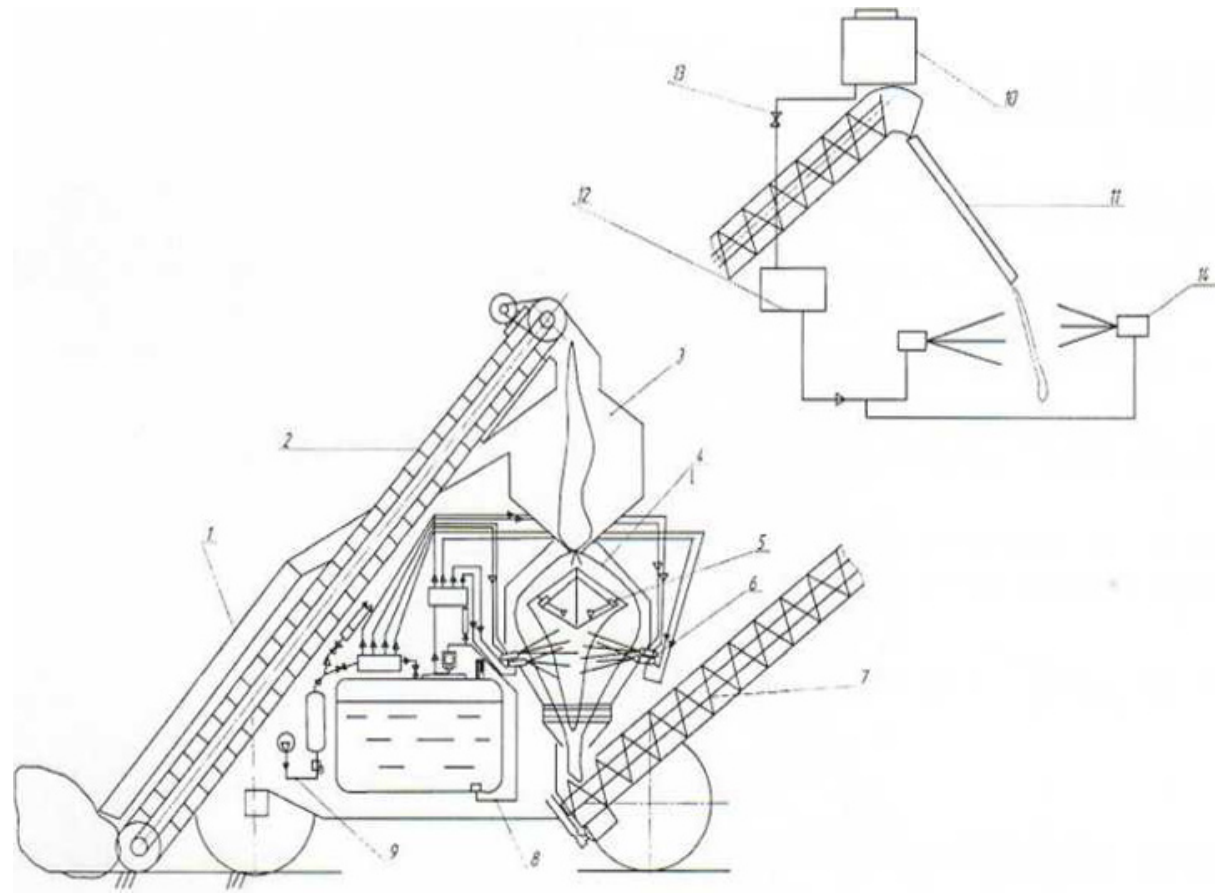

Fig. 1. The technological process of the machine

1- pitched pipe; 2- loading conveyor; 3 - hopper for seeds; 4 - adapter; 5,6,14-pneumatic slot sprayers; 7- screw; 8 - hydraulic drive; 9 - pneumatic drive; 10 - tank with working fluid; 11- pitched board; 12- equalizing tank; 13- crane.

The seed material is brought to the lifting pipe of the loader (scraper conveyor) with the help of screw feeders that capture it when the machine moves along the seed shoulder, then the scraper conveyor feeds it to the distribution loading screw. The seed material is distributed along the width of the auger and fed into the hopper, where the seeds accumulate. Through the holes that are regulated by the flap, the grain from the hopper enters the vibrating pitched boards, on which the material is distributed evenly, which is a necessary factor for high-quality etching. The vibrator, with the assistance of a pulse generator, creates vibrations and since the angle of inclination of the pitched boards is less than the angle of internal friction, a uniform distribution of the material is ensured. From the pitched board, the seeds fall freely in an even layer into the cavity of the working chamber on an air-drop jet formed by a pneumatic slot sprayer. By excess pressure, the working fluid is fed from the tank to the equalizing tank, then from it to the distribution manifold, and then to pneumatic slot sprayers. In the sprayer, the working fluid is sprayed to a misty fine-dispersed state and enters the flow of seed material. The flow of swirled compressed air flows out of the slot nozzle of the sprayer at a high speed and thus the 
chemical is sprayed. Compressed air is supplied from the compressor to the sprayer through the receiver, the pressure regulator, the collector. A stationary compressor of the grain harvesting unit is used for the operation of the machine, and it is possible to use a mobile compressor as well.

The processed seed material is fed into the pipe of the discharge auger, where it is captured by the auger, is risen to a height of $2.7 \mathrm{~m}$ and is unloaded. Unloading of the etched grain is possible both in bags and in burts. The grain coming from the screw conveyor falls on a rolling board-distributor and is additionally treated with protective and stimulating liquids that cannot be used in tank mixtures with pesticides or other drugs. The processing scheme and elements of the basic design of the machine are similar to those used when processing seed material in the mixer-adapter with the "Mobitox" etchant.

We have conducted the study of the performance of the sprayer depending on the diameter of the feed tube and the pressure in the pneumatic system of the spraying device.

For the test, there was used the installation to determine the performance of the sprayer. At the same time, the measuring cup with a platform was fixed on a tripod, fixed at a height of $0-30 \mathrm{~cm}$ relative to the sprayer (it corresponds to the position of the equalizing container).

For the tests, a sprayer with a feeding tube diameter of $3 \mathrm{~mm}$ was used. Water from a measuring cup and air from a compressor unit were supplied to the sprayer by gravity. The pressure in the pneumatic system was set by a pressure regulator at $0.15 \mathrm{MPa}$. The time of consumption of $100 \mathrm{ml}$ of liquid was measured and the performance of the sprayer was calculated. Then similar tests were carried out at the pressure in the pneumatic system of $0.2 ; 0.25 \mathrm{MPa}$. After that, feeding tubes with a diameter of 3,4,5 $\mathrm{mm}$ were installed in the sprayer and the experiments were repeated.

Tubes of various diameters, 3, 4, $5 \mathrm{~mm}$, were used to conduct experiments and achieve different median mass diameter of droplets (MMD). The choice of these parameters is due to the fact that a diameter of less than $3 \mathrm{~mm}$ is undesirable, since it is possible to clog the feeding tube, and at a diameter of $5 \mathrm{~mm}$, the maximum required MMD and liquid flow are achieved.

Based on the results of the experiments, graphs of the dependence of parameters of the sprayer are constructed and shown in figures (Fig. 2, Fig. 3)

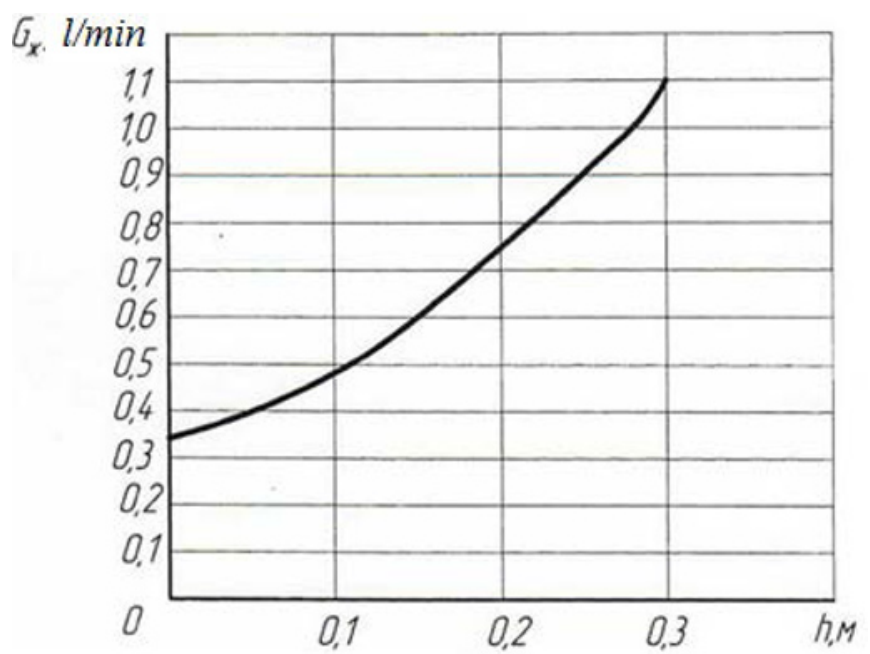

Fig. 2. The dependence of the performance of the sprayer on the position of the equalizing tank.

The graph shows that the capacity of the sprayer varies from 0.3 to $1.01 / \mathrm{min}$ when the equalizing tank is positioned relative to the sprayer from 0 to $0.3 \mathrm{~m}$. When installing the 
sprayer at a height below $0.1 \mathrm{~m}$, the performance increases slightly within $10 \%$.

And productivity increases with an increase in the diameter of the feeding tube.

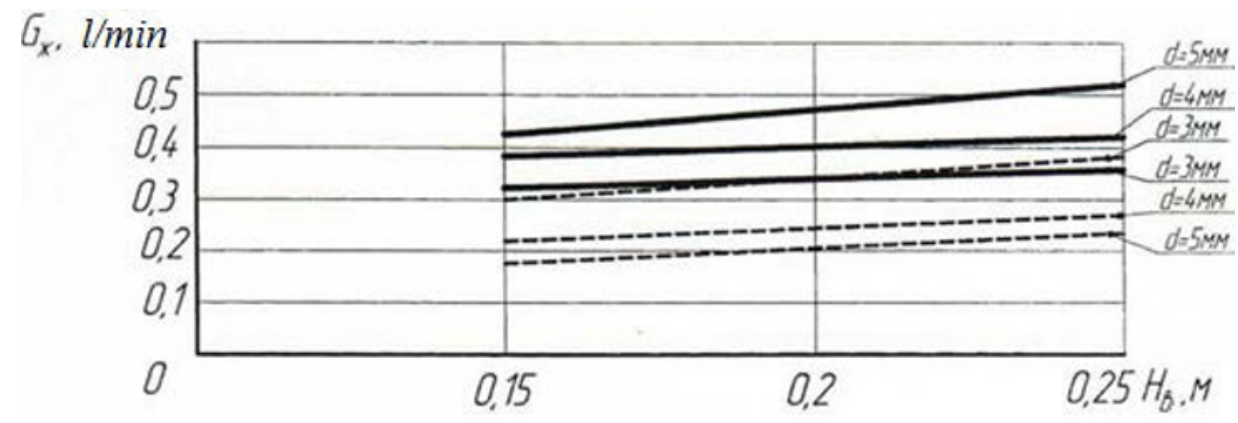

Fig. 3. The dependence of the sprayer's performance on the diameter of the feeding tube. sprayer with a lemniscate nozzle profile, nozzle dimensions $0.35 \times 7.5 \mathrm{~mm}$. sprayer with a lemniscate nozzle profile, nozzle dimensions $0.35 \times 5 \mathrm{~mm}$.

The graph shows that a sprayer with nozzle parameters of $0.35 \times 7.5 \mathrm{~mm}$ has about twice the performance compared to a sprayer with a nozzle with a profile of $0.35 \times 5 \mathrm{~mm}$.

The performance with a change in the diameter of the feeding tube varies within $15 \%$ for a sprayer with nozzle parameters $0.35 \times 7.5 \mathrm{~mm}$.

The performance of the sprayer changes slightly (within 7\%) with a change in the pressure in the pneumatic system.

\section{Conclusions}

The analysis of the process of operation of the pneumatic slot sprayer showed that the range of the sprayed droplets to the treatment object depends mainly on the air pressure in the pneumatic line, which can vary from 10 to $3.0 \mathrm{MPa}$ and is $1.2 \ldots 1.4 \mathrm{~m}$. The flow rate of the working fluid by the pneumatic slot sprayer can vary from 0.05 to $1.2 \mathrm{l} / \mathrm{min}$. The performance of the sprayer depends on the shape of the jet-forming nozzle.

It is recommended to install a device in the form of a pitched distribution board and a device in an adapter on a mobile or stationary etcher, loading and unloading machines for treating seeds with protective and stimulating liquids not only with pesticides, but also with bio and bactopreparations.

The etchers of various designs can be upgraded by using a device with pneumatic slot sprayers of the KubSAU design.

\section{References}

1. Pat. 2693258 Russian Federation. Device for potato tubers treatment with protective and stimulating liquids during planting [Text] / S. M. Borisova, S. K. Papusha, N. P. Chistyakov, N. A. Nikitenko, applicant and patent holder Federal State Educational Institution of Higher Education "Kuban State Agrarian University".

2. S. M. Borisova, K. V. Ermakov, D. M. Nedogreev, Rural mechanical engineer, Advantages of ultra-low-volume sprayers Ejection-slot sprayer for seed etching [Text], No. 3, pp. 10-11, (2015).

3. Pat. 237367711032008 Russian Federation. Seed etcher [Text] / E. G. Shevchenko, G. G. Maslov, S. M. Borisova; applicant and patent holder Federal State Educational Institution of Higher Education "Kuban State Agrarian University". 
4. S.M. Borisova, N. A. Rinas, Rural mechanical engineer, Advantages of ultra-lowvolume sprayers Ejection-slot sprayer for seed etching [Text], № 9(67), P. 16, (2014).

5. S.M. Borisova, S.K. Papusha, N.A. Nikitenko, In proceedings: E3S Web of Conferences, Optimization of parameters of the spraying device at etching of potato tubers, P. 00014, (2019).

6. S.M. Borisova, S.K. Papusha, E.M. Sivovalov, In proceedings: IOP Conference Series: Materials Science and Engineering. Series "International Conference on Modern Trends in Manufacturing Technologies and Equipment, ICMTMTE 2020 Machine Science, Mechanization, Automation and Robotics", The process of ultralow-volume seed etching with an experimental device, P. 052062, (2020).

7. S.K. Papusha, D.A. Kotov, V.V. Zhadko, In proceedings: E3S Web of Conferences. Series "International Conference on Modern Trends in Manufacturing Technologies and Equipment, ICMTMTE 2020", Technological features of a combined soil processing machine and a sprayer, P. 01026, (2020). 